

\title{
Artificial Intelligence in Public Administration
}

Jan Etscheid

\section{To cite this version:}

Jan Etscheid. Artificial Intelligence in Public Administration. 18th International Conference on Electronic Government (EGOV), Sep 2019, San Benedetto del Tronto, Italy. pp.248-261, 10.1007/9783-030-27325-5_19. hal-02445801

\section{HAL Id: hal-02445801 \\ https://hal.inria.fr/hal-02445801}

Submitted on 20 Jan 2020

HAL is a multi-disciplinary open access archive for the deposit and dissemination of scientific research documents, whether they are published or not. The documents may come from teaching and research institutions in France or abroad, or from public or private research centers.
L'archive ouverte pluridisciplinaire HAL, est destinée au dépôt et à la diffusion de documents scientifiques de niveau recherche, publiés ou non, émanant des établissements d'enseignement et de recherche français ou étrangers, des laboratoires publics ou privés. 


\title{
Artificial Intelligence in Public Administration
}

\author{
A possible framework for partial and full automation \\ Jan Etscheid ${ }^{1}$ \\ ${ }^{1}$ Zeppelin University, Am Seemooser Horn 20, 88045 Friedrichshafen, Germany \\ jan.etscheidezu.de
}

\begin{abstract}
The constant increase of technical possibilities makes the automation of processes more and more attractive for the public administration. Due to the advances in Artificial intelligence, processes can be automated today which only a few years ago had to be carried out by humans. But not all administrative processes can be automated from a technical point of view. From the multitude of several thousand administrative procedures, decision-makers must select those processes which are deemed appropriate for partial or full automation. This paper seeks to present a possible framework to evaluate opportunities for automation through the decomposition of administrative procedures.
\end{abstract}

Keywords: Artificial Intelligence, Process Automation, Smart Government.

\section{$1 \quad$ Introduction}

After the successful implementation of automation processes in the private sector, the idea of the automation of processes is now taken up by the public administration. Although decision-supporting systems have been used in the German administration for some time, the full automation of processes has become the centre of attention only recently. The reason is a new legal regulation which came into force at the beginning of 2017. The Federal Administrative Procedure Law basically permits the full automation of all administrative procedures if there is no necessity for assessment or discretion and if a specific legal regulation has been made for the individual process [1]. Additionally, limits in terms of technical transformation persisted for quite some time. Nowadays, however, numerous activities can be automated, which just a few years ago had to be carried out by humans. To pursue an implementation, it must be known which procedures are suitable for automation in the first place. In view of the large number of administrative procedures, a categorizing scheme is required. Said scheme can be used to assess the automatability on the basis of overarching criteria.

The present article demonstrates a framework for analysis to assess the automatability of administrative procedures. Conclusively, the research question is: "Which criteria can be used to assess the automatability of individual decision phases in administrative procedures?". In a first step, the approaches of artificial intelligence, process automation, as well as the course of an administrative procedure, will be presented based on previous literature and research in relation to the application case. In a second step, the 
administrative procedure is broken down into its sub-processes, which are examined individually. Finally, results as well as recommendations for action are presented.

\section{Terminologies}

\subsection{Artificial Intelligence}

How to define artificial intelligence is a difficult question. At present, there is no generally accepted definition. If anything, it is a term which is collectively used to describe different technologies and approaches in different degrees of maturity for the simulation of intelligent behaviour by technical systems. A fortiori, conceptual clarity is of utmost importance in any research involving the idea of artificial intelligence.

The term artificial intelligence differs from natural intelligence, which is attributed to humans. In colloquial language, people who are able to think quickly and who manage to solve complex problems are referred to as intelligent. The debate continues of whether intelligence is a relatively simple or highly complex information-processing practice [2]. Scientifically controversial intelligence tests measure primarily mental abilities such as the knowledge of words and their context-dependent meaning, speed and precession in arithmetic tasks, or deductive reasoning using a sequence of numbers or symbols [3].

In the scientific realm, the definition of intelligence diverges as well. William Stern, author of the intelligence quotient IQ, defined intelligence as "[...] the general ability of an individual to consciously adjust his thinking to new demands, a general mental adaptability to new tasks and conditions of life" [4]. A different approach is conducted by a group of world-leading intelligence researchers who defines intelligence as "[...] a very general mental ability that includes, among other things, the ability to reason, plan, solve problems, think abstractly, understand complex ideas, grasp quickly and learn from experience" [5]. Howard Gardner's theory of multiple intelligences, published in 1998, goes far beyond this classical concept of intelligence by defining naturalistic, musical, spatial, physical, intrapersonal and interpersonal intelligence in addition to linguistic and logical-mathematical intelligence [6].

Based on this broad variation of concepts concerning intelligence, the question arises of how artificial intelligence (AI) can be defined. The term "artificial intelligence" has been used in science since the 1950s. In 1966 Marvin Minsky defined AI as "[...] the science of making machines do things that would require intelligence if done by men" [7]. The Turing Test, developed by Alan Turing at the beginning of the 1950s, deals with the differentiability of interpersonal communication from communication with a technical system, whereby he optimistically assumed that by the year 2000 it would no longer be possible to distinguish between humans and computers [8]. Steven Finlay describes $\mathrm{AI}$ as the "replication human analytical and/or decision making capabilities" [9]. A broad working definition by Klaus Mainzer describes systems as intelligent if they "can solve problems efficiently on their own" [10]. 
Whereas practical approaches toward artificial intelligence usually involve the processing of very large amounts of data, artificial neural networks or self-learning algorithms. Scientists differentiate between weak AI, strong AI and sometimes even super intelligence. Weak AIs are usually developed and used for a specific type of applications, including expert systems, speech recognition, navigation systems and translation services [10]. Applications based on weak AI are already widely used today; they even gained entry in the everyday life in the form of intelligent search suggestions or optimized route calculations. Within the theory of multiple intelligences, weak AIs are primarily the replication of linguistic and logical-mathematical intelligence. This understanding is strongly reflected, for example, in the definition of Finlay.

By contrast, strong AIs describe systems that are able to independently think, plan, learn and make logical decisions under uncertainty [10]. The concept of super intelligence is based on a system that is intellectually superior to any human being. Such a system should therefore be able to map all dimensions of multiple intelligences better than any human being [10]. So far, and probably also in the upcoming decades, strong artificial intelligence and superintelligence are reserved for science fiction. However, such representations still strongly shape the ideas and expectations of artificial intelligence. The current developments are all at the level of the weak AI. Nevertheless, systems in certain areas have already succeeded in surpassing human performance. Programs like Deep Blue or Alpha Go could beat the world's best players in Chess or Go; but they were developed especially for this task. They do not succeed in acquiring the knowledge of other games to the same extent as humans do. In this respect, these cases remain in the category of weak AI, even though the human performance was partially exceeded and some elements assigned to the category of strong AI already exist.

Early AI systems from the middle of the 20th century, often referred to as expert systems, were basically comprehensible for the developer and user because they operated according to defined rules. These expert systems were primarily intended to present relationships transparently in order to explain multi-causal phenomena. While this traceability can be regarded as a strength, early AI systems could only inadequately depict the real world with its uncertainties. Newer AI technologies take exactly this circumstance into account: rule-based algorithms are not able to map a reality which is characteristically complex and uncertain. Self-learning technologies, which deliver a better result but whose solution cannot be understood, are often called black boxes. The research area "Explainable AI" tries to present the functionality of algorithms of artificial intelligence in a comprehensible way, not only to create transparency and trust in systems, but also to generate additional knowledge by recognizing logics and contexts. Especially in public administration, which must be democratically controlled, the transparency and verifiability of decisions is an elementary prerequisite [22].

The term artificial intelligence thus describes a broad concept in different stages of development. While weak AIs aim at the partial simulation of human intelligence, focusing on logical-mathematical and linguistic intelligence, strong AIs and super intelligence try to emulate and surpass humans in every aspect of intelligence. However, since there is a great deal of uncertainty at this stage as to whether a truly strong AI can ever be realized, this work is based on the understanding of weak AI. From this point 
onward, if we talk about artificial intelligence, we mean systems that simulate the logical-rational and linguistic elements of human intelligence.

\subsection{Process Automation}

The term automation originates from the industrial context. Automated systems are systems that have the technical ability to work independently. On a simple level, these can be everyday things such as vending machines for drinks or tickets. According to the definition, automation is the transfer of functions from humans to artificial systems [11]. Process automation in turn represents a specification of the broad concept of automation. In public administration, the majority of processes are decision-making processes [12]. Deciding in this context means choosing between two or more alternatives. Although it is the outcome of decisions which finds most attention, the decision itself must be seen as a process with several phases. The psychological decision theory is based on six stages: problem definition, determination of alternatives, evaluation of alternatives, selection, implementation and evaluation [13].

Process automation can itself be divided into several stages. Overall, processes can usually be subdivided into several sub-process steps, such as the phases of the decisionmaking process mentioned above. Sub-process automation refers to the transfer of individual sub-process steps to technical systems. One or more sub-steps are executed by a system and then inserted into the overall process by a human operator. The human being is responsible for the non-automated sub-steps and the coordination of the overall process. Full automation, on the other hand, includes the transfer of all sub-steps as well as the coordination of the entire process to a technical system. Ergo, the entire process runs without human intervention [14].

The possibility of a partial automation of administrative procedures has been anchored in administrative procedural law for many years and is also widely used in many areas. At the beginning of 2017, however, the legislator also specified the possibility of full automation. This means that administrative files can be processed completely automatically as long as there is no necessity for assessment or discretion and a special legal basis has been created for the individual administrative procedure [1]. This illustrates the increasing relevance of process automation in public administration.

\subsection{Administrative Procedures}

As almost every administrative action is based on decisions previously made, Administrative Science can be placed within the field of Decision Science [15]. Conclusively, this article considers the administrative process as a decision-making process. To identify automation potentials within an administrative procedure, it is necessary to divide the process into individual sub-steps.

Administrative decisions are primarily legal decisions. If the general psychological model of decision-making is adapted to a legal case, the administrative procedure can be divided into seven main phases (whereby said phases can be subdivided into several partial decisions) [16]: 
- Recognition of the problem

- Fact-finding

- Norms finding and norms concretisation

- Application of law and subsumption

- Legal consequence analysis

- Realization

- Evaluation

The level of problem recognition corresponds to the orientation phase in the classic model of decision-making. The first step is the awareness by the administration of the necessity for a decision. On the one hand, the administration itself can decide whether to open an administrative procedure in accordance with the official principle. It will receive the necessary information from various sources such as the media, other government agencies, citizens, interest groups or, increasingly, smart objects. On the other hand, there are administrative procedures which are only initiated upon request. In such cases, the administration must first check the identity and eligibility of the applicant [17].

The search phase of the decision-making model corresponds to the fact-finding phase of administrative decisions. The fact-finding intends to collect a basis of correct and complete information on which the decision can be made. Here, too, the administration relies on various sources of information. The authority has partial discretion as to which information is relevant in the specific case and at which point a sufficient amount of information was collected. In doing so, the authority must weigh different factors such as the need for additional information and time constraints. The scope of the decision and the complexity of the matter must also be taken into account [17].

The norm finding and concretisation describes the phase of finding and assigning the relevant legal norms. The facts of the case are analysed to determine which legal norms are to be applied in the individual case at hand. Indeterminate legal terms which are frequently used in administrative law sometimes offer a certain leeway for interpretation and assessment which call for an application suited to the individual case. There is a fluent transition to the phase of legal consequence assessment [17].

If the relevant legal norms are determined, possible legal consequences must be determined. During the step of subsumption a rough distinction can be made between bound and discretionary decisions. In the case of a bound decision, the legal consequences are already given by the law. In many cases, however, the legal consequence does either not result directly from the norm or must be specified beforehand. In this case, the administration has a leeway which is referred to as discretion. A distinction can be made between development fairs, on which the administration acts, and selection fairs, which select the measure. In the case of discretionary decisions, the administration must interpret the standard in such a way that the effect intended by the legislator is achieved in the individual case. At the end of the legal consequence investigation, the administration decides what action it will take [17].

After the decision-making process follows the implementation stage. However, for the question at hand the actual implementation is only of secondary importance. The presentation and justification of the administrative decision appear to be more relevant. 
In most cases, the administration is legally obliged to justify how it reached a certain decision. This serves not only the purposes of transparency and comprehensibility, but also rationality. As a rule, rational decisions are considered to be justifiable and not the result from personal impressions [18].

The decision-making process is concluded by the control and evaluation phase. The result of the decision is thoroughly assessed to see whether the actual result corresponds to the result initially intended. Therewith, future decisions could be adjusted on the basis of previous experience. This does not mean, however, that in the case of multiple decisions each one has to be controlled for individually. Basically, a distinction can be made between external and internal control. Since further specification is not necessary for the investigation of the automatability, the evaluation and control phase may be neglected at this point.

\section{Identifying entry points for automatization in administrative tasks}

In order to assess the suitability of administrative procedures for partial or full automation, the phases of the decision-making process must be considered individually.

\subsection{Problem Definition}

As previously demonstrated. the level of problem recognition can be divided into the cases of initiation by proposal and initiation on the basis of the official principle. If administrative proceedings are initiated by an external proposal, the first phase is essentially limited to the identification of the applicant and the examination of eligibility. Identification and eligibility are often closely linked, since eligibility is based, for example, on citizenship, place of residence, or age. In this respect, the primary task is a doubtless identification. In Germany, the electronic identity card is mainly used for this purpose; internationally, other solutions such as PIN/TAN systems or mobile phone signatures exist as well. At this point, it is crucial to make the identification process as easy as possible for the citizen in order to increase the acceptance for its usage. As the usage of electronic ID cards is neither widely spread nor very popular in Germany, artificial intelligence could be used in conjunction with a PIN procedure. The lower level of security of the PIN procedure could be combined with the application of a webcam which is able to generate a biometric comparison of the applicant's face with the photo stored in the passport. A similar system is already used for the automated border control "EasyPASS" [19].

The case of a problem identification initiated on the basis of the official principle proves to be more difficult. First of all, the administration must recognise whether it is necessary to initiate a procedure. Simply put, the administration must decide if the actual values deviate from the target values. An easy example is the usage of an algorithm which can detect whether and when the amount of particulate matter measured exceeds 
the permissible limits. The simplicity is rooted in the quantifiability of the circumstances. Then again, many problems evade such quantitative data. Rather, the administration is dependent on information from different sources which must be evaluated, classified and inserted into the overall context. Not only the ability to weigh and evaluate, but also the use of experience values is indispensable. This step cannot be performed by conventional algorithms. At this point the use of artificial intelligence is necessary [10]. The AI must "understand" the target goal, which cannot be defined directly on the basis of individual key figures. One example is the problematic of advertising installations which may contain disfiguring characteristics. In this case, neither clear colours nor sizes are sufficient reference points. The evaluation necessitates the understanding of the individual case. To be more precise, the AI must understand how individual components are connected and how their formation makes up the entire system. The same applies to the actual state. Finally, the AI-based system must be able to compare the complex states of the actual and targeted state in such a way that blatant deviations are detected. At least in complex constellations, this requires the ability to think logically independently which is attributed to the strong AI not yet available today. Instead, less complex cases can be automated even with weak AIs. The ability to automate thus strongly depends on the quantifiability of the information as well as the complexity of the case. In this phase, multi-agent systems could be used to record and process situations from different perspectives. Several intelligent assistants can be linked together to detect deviations from the desired outcome.

In the problem definition phase, the following guiding questions assist in the evaluation of possible automatability: Is there an external request or must the administration itself recognize the necessity of a procedure? In the case of official procedures, to what extent are criteria for initiation prescribed by law, in the sense of fixed limits or indefinite legal concepts? To what extent is the direct measurability of these criteria possible or does it require an individual interpretation?

\subsection{Fact-Finding}

In case of the initiation of the administrative procedure, the fact-finding state follows the first stage of problem definition. The fact-finding stage is an essential and significant part of the administrative procedure. In this phase, all information must be collected which are deemed necessary for the decision. Thus, the basis for the final judgement must be created.

In general, the degree of structuredness of the procedure is decisive for automation. In many administrative procedures, it is clearly defined which information must be used for the decision. A simple case would be the comparison of the information provided by the applicant to the data available to the administration, e.g. reporting data. If the necessary information is defined clearly, it must first be ensured that an automated system can collect and process this information. Should the decision-relevant information be clearly definable, an automated information collection is possible which enables the creation of a decision basis. There are many advantages to automation. Technical systems can process a multitude of information in almost real time. Especially in combination with smart objects and cyberphysical systems, it is possible to create decision bases which rely on actual and current facts instead of on models and calculations [21]. 
Information that is solely available in unstructured forms, such as oral statements or informal texts, however, poses a difficulty. In the context of fact-finding, unstructured information must already be brought into a structured form so that the information can be used in the upcoming steps of the process. Similar to the previous phase, multi-agent systems are a suitable option to collect and process information from different sources.

The automation of the fact-finding process is even more difficult in cases in which the required information is derived from the concrete facts of the case. Formulations such as "Information that is important for the individual case must be taken into account" leave some leeway as to which information is to be regarded as significant. In addition, most issues offer a multitude of information available for judgment which requires a preset point in the process at which sufficient information is available as a basis for decision-making. An example would be the proceedings involved in acquiring a building permit. As stakeholders have the right to submit information they perceive as relevant in the decision-making, the first step would encompass an evaluation as to which information is relevant for the present case and which aspects might be neglectable. The wording "relevant information" must be interpreted according to the individual case. Automation with the help of weak artificial intelligence only seems possible when a certain degree of structure is present. This does not necessarily have to be a matter of legal requirements; often, there are also regulations from administrative practice. It becomes difficult, however, if the necessary information only appears in the middle of the procedure. A high proportion of unstructured information also makes automation more difficult, since these must first be translated into a structured form in order to examine their relevance to the individual case. Thus, an AI would have to be able to understand context-based natural language. In order to determine the facts of the case, it can therefore be stated that clearly defined information and the existence of structured information facilitate automation in advance. With increasing openness regarding the relevant information, an increasing degree of unstructuredness and growing complexity, a more powerful AI is needed for automation.

In the phase of fact finding, the following questions can guide the analysis. Is the information that serves as a basis for decision-making clearly defined or must it be determined individually in each individual case? Is the information available from clearly defined sources or does it have to be collected on a case-by-case basis? Is the information available in machine-readable formats?

\subsection{Finding and concretising legal norms}

If there is a sufficient basis of information for decision-making, the norms relevant to the decision must be determined. One possible approach is the distinction between proposed procedures and official procedures from the problem recognition phase. In the case of a proposed procedure, the relevant standards are usually firmly defined. Conclusively, the norms of the case are already determined by the relevant legal framework. The application for a passport, for example, is based on clearly defined rules of law which shall in any event apply to the application. The procedure becomes more difficult if there is no formal application and the relevant law must be derived from the individual case. For this purpose, the collected information must be understood in its entire 
breadth and complexity in order to be able to determine the relevant norms. If, for example, excessive noise emissions are found from a commercial enterprise, the administration must first examine the legal basis on which it can act in this case. Furthermore, individual criteria, such as the location in a residential area, must be taken into account. At this point, the effectiveness of the artificial intelligence would have to rise with the complexity of the situation. It is questionable whether the present state of a weak AI would be suited to fulfil this task [20]. Expert systems are able to technically represent the content and interpretation of legal standards and thus assign them to the appropriate circumstances.

Many difficulties arise in the phase of the application of the law as this is closely linked to finding the appropriate norm. Particularly in administrative procedural law, there are numerous indeterminate legal terms which cannot be applied to individual cases without further concretisation. While many indeterminate legal terms can be relatively easily operationalized due to their regular use in administrative practice, others have to be embedded in the individual case in a much more individualised way. In addition, there are complex procedures such as the interpretation of legal norms, the linkage of the literal law text with the lived administrative practice and the appropriate jurisdiction. At the present time, it still seems impossible to automate the phase of the application of law in the case of complex facts and norms in the context of indefinite legal terms. Feasible for automation processes would be those norms which can be applied on the basis of clear criteria and require only little interpretation in individual cases. A certain degree of interpretation based on previously clearly defined criteria can already be provided today by weak AIs.

Key questions in the phase of norm finding and concretisation resemble the guiding questions of the problem definition phase as the underlying legal norms are often clearly defined within the framework of application procedures. It is also relevant whether indefinite legal terms make the classification more difficult.

\subsection{Determination of legal consequences}

The core of the decision-making process is the determination of legal consequences based on the facts established and the norms relevant to the case. Here, the distinction between bound and discretionary decisions, which is also used by the German legislator in the context of full automation, can be used. It seems obvious that bound decisions are better suited for automation, since they result in legal consequences without further leeway from the law. Bound decisions therefore do not represent a major challenge for automation in the phase of legal consequence determination [20]. These cases can even be automated without AI by using if-then decisions. The situation is different if there is scope for discretion or assessment. Primarily, the leeway was granted to the administration to achieve the intended results in individual cases. In order to be able to automate such decisions, the system would have to be able to detect the leeway, understand the intended effect of the legislator and then make the necessary decision within the available scope. If said scope is not always directly apparent from the text of the law, and existing scopes are not available through practical experiences, an automated recognition of the leeway appears to be, at least at the present, out of the question. One best 
case scenario which seems feasible would be a margin with clearly stated criteria, previously defined by humans. However, since the scope for decision essentially serves to establish justice in individual cases and often also contains ethical components, automation should only be used extremely carefully and restrictively. Understandably, bound administrative decisions offer much greater potential at this point. The missing technical means for the automation of decisions with considerable leeway render the German legislator sceptical towards the full automation of administrative procedures [21]. The use of the rule management systems offers the possibility of applying rules (defined as norms through the application of specific framework conditions) and presenting them transparently.

The most important question at the legal consequence assessment stage is therefore whether the decision is of a tied or a discretionary nature. Furthermore, one must consider whether clear criteria for the exercise of discretion have been defined. Conclusively, are the objectives to be achieved by discretion measurable on the basis of clear criteria?

\subsection{Implementation}

In the present case, the implementation phase shall be reduced to the preparation of an official notification. As the implementation of numerous administrative decisions goes far beyond this scope, there is a great deal of potential for automation. However, since the present article refers to the process of administrative decisions in the narrower sense, the implementation beyond the preparation of an official notification may be neglected for now.

If the implementation is regarded solely as the creation of an official notification, this phase represents a relatively formalised process. Standardised elements such as instructions on legal remedies, for example, can only be adapted to the case and be inserted automatically as text modules. In the notice the result of the preceding process, in particular the standard finding and legal consequence determination, is represented in writing. For the purpose of comprehensibility most administrative decisions must be justified according to law. To automate the creation of notices, the system must be able to present and justify the administrative decision in natural language. While conventional algorithms can only process data in machine-readable form, artificial intelligence is already partially able to understand and speak natural language. Hence, in many cases the presentation of the result of the decision-making process is not a major difficulty anymore. Yet, the justification and transparency of the administrative decision appears to be more difficult, especially since AI is often referred to as black box technology. Explainable AI can make an important contribution in this respect in the future. Here it appears decisive to what extent the decision criteria are given to the system and to what extent the system itself classifies and weights factors.

In the context of the present consideration with the focus on the preparation of the official notification, the following questions must be clarified: to what extent can the results of the procedure be presented in natural language? And to what extent can the decision itself be presented transparently? 


\subsection{Evaluation}

The final phase of control and evaluation is relatively similar to the problem identification phase. Here, too, the targeted and actual states are compared. As this has already been explained in previous passages and monitoring and evaluation are not at the core of the decision-making process, we will not go into further detail for now.

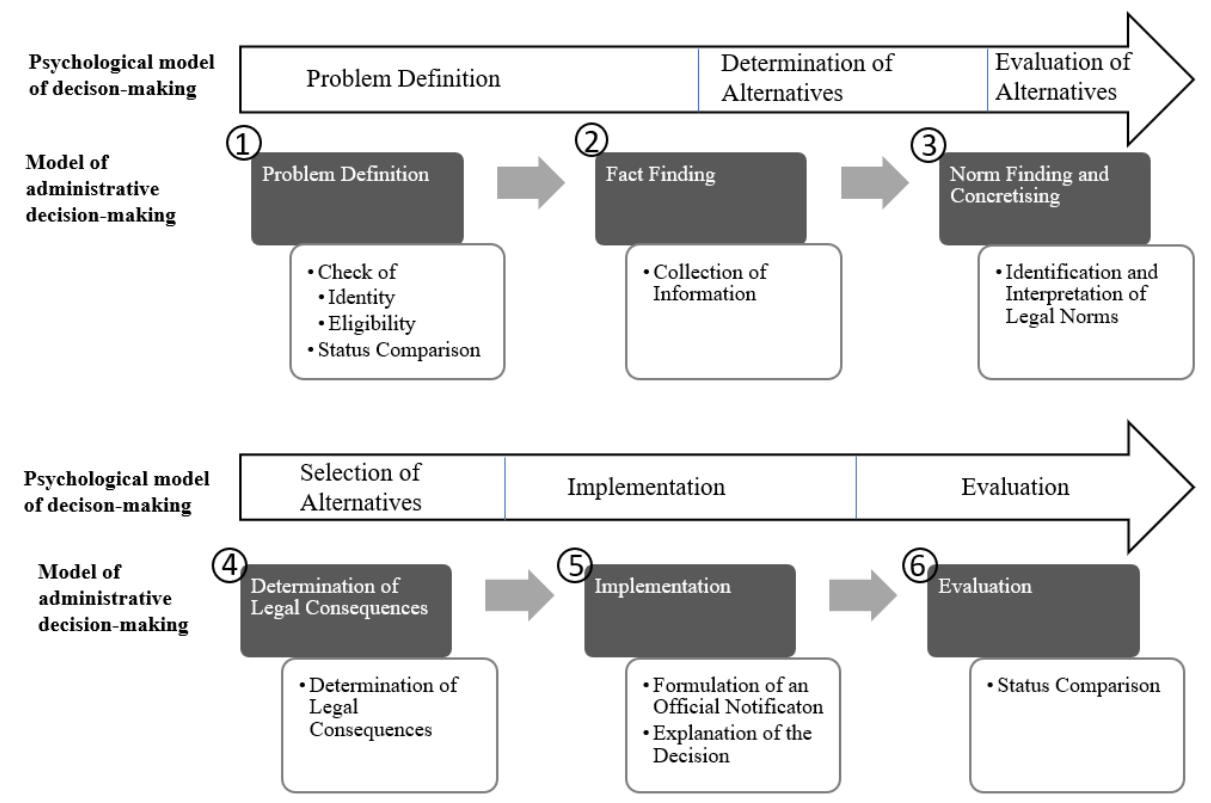

Fig. 1: Process sequence in the psychological and administrative model

\section{$4 \quad$ Levels of automation}

If the administration wants to partially or completely automate procedures, it seems advisable first, to consider the individual steps of the administration procedure; second, to define concrete contents and requirements and third, to evaluate the possibility of automation. Overall, it can be concluded that a generally decreasing degree of pre-set structure and an increasing complexity intensify the difficulty for automation.

If the administrative procedure is broken down into the different phases, the possibility for automation can be individually evaluated for each step. Ergo, one does not consider the entire process, but only its sub-processes. For this, algorithms can be evaluated in respect to their suitability for automated stages in the administrative procedure. The result would be automatically handled phases whereby the output would be delivered to the human supervisor for further processing. It is also possible for a human processor to enter the input, required for an automated step, into a system so that the subsequent process can run automatically. In order to fully automate an administrative process, it would be necessary to perform all process steps and the coordination of the 
entire process automatically. In a nutshell: procedures, which do not contain automatable components, are not suitable for partial or full automation. Nevertheless, technical systems can also support the human decision-maker in such procedures, for example by automatically collecting information, graphically processing information or by giving suggestions for evaluation [14].

To translate all administrative procedures into automated systems appears to be an impossible task. Conclusively, the present paper suggests to deconstruct administrative processes into individual phases in order to evaluate which individual stages can be automated and which parts must be (at least at present) left to the human evaluation. With growing technical possibilities and experience, it is likely that more and more phases can be automated in the course of time.

\section{Conclusion}

Against the background of tight budgets, lack of skilled staff and pressure for more customer-friendly services, politicians and the general public are often pushing for the rationalisation and automation of administrative procedures. Especially in the light of new technical possibilities offered by artificial intelligence, new potentials seem to be realizable. The article has defined artificial intelligence and automation in an administrative context and demonstrated the different phases of administrative procedures which might offer possibilities for automation.

There are over 5000 different administrative procedures in Germany. In order to be able to assess their automatability, the procedures should be mapped as digitally as possible in order to be able to analyse the individual steps. It deems a good idea to use a scheme for simpler classification. The explanations in this paper have shown that the different phases of an administrative procedure entail different sub-processes which in turn offer different opportunities and challenges for automation. In the problem recognition phase, the ability to synchronize complex situations is particularly important. The fact-finding phase requires the collection of information as well as the subsequent structuring and classification. The norm finding process presupposes an understanding of legal texts, the actual wording, the everyday administrative practice as well as the jurisprudence. The phase of legal consequence determination used here within the context of decision-making in the narrower sense, contains the allocation of legal consequences partly under use of evaluation leeway. In the context of the paper, the phase of implementation was regarded as answer production; conclusively it focuses on the representation and reason for the decision. In the final phase of control and evaluation, the actual state is again compared with the targeted state. An autonomous system or an AI must be able to perform these tasks in order to automate the step. Some steps are obviously better suited for automation than others. In particular, the phases of norm finding and determination of legal consequences are currently difficult, since technical systems are not yet in a position to interpret legal texts beyond the wording. In general, it can be said that a high degree of structure and low complexity facilitate automation. The extent of the defined space of which information must be consulted and how these are weighted against each other should be provided by humans as far/much as possible. 
Furthermore, the quantifiability of information represents an important aspect towards the extent to which it can be converted into machine-readable formats. Following this paper, future research would focus on the in-depth analysis of the individual phases and the development of concrete indicators for the degree of automation. This would result in an instrument usable by the administration and political decision-makers to assess the automatability of specific phases or entire procedures.

Today's weak AI already offers a number of possibilities, especially if it was developed for a specific task. Nevertheless, there is also fear and scepticism about the use of $\mathrm{AI}$ in the current social debate. Despite all technical possibilities, the requirements of the rule of law and the demands of citizens must be taken seriously, especially in the context of public administration. Even automated administrative decisions must always be comprehensible for the citizens involved. In addition, international examples from Australia and Norway already show how quickly the public's trust in automated decisions can be lost. Particularly in sensitive areas such as social security, where administrative decisions have a direct influence on people's livelihoods, systems should only be used when the error rate is acceptable. Questions about the responsibility for automated decisions or the right of a person to control decisions are still not sufficiently clarified. These aspects demonstrate the vast range of the topic which is influencing societies, politics and economics and will do so even more in the future. Evidently, important questions remain which go way beyond the scope of this paper. These must be addressed, however, if the implementation of automated processes should be successful.

\section{References}

1. Braun Binder, N.: Weg frei für vollautomatisierte Verwaltungsverfahren, in: Jusletter IT, 22. September 2016.

2. Franken, S.: Verhaltensorientierte Führung. Gabler Verlag, Wiesbaden (2010).

3. Katz, M.: IQ-Tests. Haufe-Verlag, Freiburg (2008)

4. Stern, W: Psychologische Begabung und Begabungsdiagnose, in: Petersen, P (ed.).: Der Aufstieg der Begabten. G.Teubner, Leipzig, Berlin (1916).

5. Zimbardo, P. \& Gerrig, R.: Psychologie. Pearson Studium, München (2004).

6. Gardner, H.: Frames of Mind: Theory of Multiple Intelligences. Harper Collins Publishers, New York (1993).

7. Minsky, M.: Computation: Finite and Infinite Machines. Prentice-Hall (1967).

8. Turing, A.: Computing Machinery and Intelligence, in: Mind, Volume LIX (236) (1950).

9. Finlay, S.: Artificial Intelligence and Machine Learning for Business. Relativistic (2017).

10. Mainzer, K.: Künstliche Intelligenz - Wann übernehmen die Maschinen?. Springer Verlag, Heidelberg (2016).

11. Lauber, R. \& Göhner, P.: Prozessautomatisierung 1. Springer Verlag, Heidelberg (1999).

12. Becker, B.: Öffentliche Verwaltung. RS Schulz, Starnberg (1989).

13. Drummond, H.: Effective decision making. Kogan Page, London (1996).

14. Etscheid, J.: Automatisierungspotenziale in der Verwaltung, in: Mohabbat, R. et al (eds.): (Un)Berechenbar?. Kompetenzzentrum Öffentliche IT, Berlin (2018). 
15. Brühl, R.: Die Verwaltungsentscheidung als Fixpunkt eines verwaltungs-wissenschaftlichen Studiums, in: Eilsberger, R \& Schmahl, H. (eds.): Auf dem Weg zur Verwaltungswissenschaft. Schriftenreihe der Fachhochschule des Bundes für öffentliche Verwaltung, (1989).

16. Erbguth, W. \& Guckelberger, A.: Allgemeines Verwaltungsrecht. Nomos Verlag, BadenBaden (2017).

17. Nesseldreher, A.: Entscheiden im Informationszeitalter. Der Andere Verlag, Tönning (2006).

18. Garrn, H.: Zur Rationalität rechtlicher Entscheidungen. Franz Steiner Verlag, Stuttgart (1986).

19. Djeffal, C.: Künstliche Intelligenz in der öffentlichen Verwaltung. Berichte des NGEZ, Berlin (2018)

20. Luthe, E.: Der vollständig automatisierte Erlass eines Verwaltungsakts nach § 31a SGB X, in: SGb 2017, Erich Schmidt Verlag, Berlin (2017).

21. Hill, H.: Was bedeutet Künstliche Intelligenz (KI) für die Öffentliche Verwaltung?, in: Verwaltung und Management 24(6), 287-294 (2018).

22. Holzinger, A.: Explainable AI (ex-AI), in: Informatikspektrum 41(2), 138-143 (2018). 